\title{
Fuzzy logic in production sequencing: the case of a cosmetics manufacturer in Brazil
}

\author{
Mario Mannarino Filho* \\ Federal University of Rio de Janeiro, \\ Cidade Universitária, \\ Rua Paschoal Lemme, 355, Ilha do Fundão, \\ Rio de Janeiro, RJ, CEP: 21.949-900, Brazil \\ Email: mario.filho@coppead.ufrj.br \\ *Corresponding author
}

\section{Peter F. Wanke}

Federal University of Rio de Janeiro,

Center for Studies in Logistics, Infrastructure and Management,

Cidade Universitária,

Rua Paschoal Lemme, 355, Ilha do Fundão,

Rio de Janeiro, RJ, CEP: 21.949-900, Brazil

Email: peter@coppead.ufrj.br

\section{Henrique L. Correa}

Rollins College,

Crummer Graduate School of Business,

Winter Park, Florida, USA

Email: hcorrea@rollins.edu

\begin{abstract}
This study aims to develop a way to improve the production sequencing practice of a case company that manufactures cosmetics located in Brazil. Production sequencing is an activity that is part of production planning and control. Our goal is to provide ways to reduce sales loss due to product stock-outs through new practices found in the literature. Simultaneously, we aimed at increasing the number of different items without sales loss thereby helping the achievement of sales goals while improving the meeting of overall demand for products. The approach proposed here includes the development of a decision support tool based on fuzzy logic. Such approach proved to be a good alternative to overcome some of the problems encountered in the case company production sequencing activity. Furthermore, the developed decision support system enabled the organisation decision-making to be more agile and dynamic. Additionally, by facilitating the incorporation of environmental complexity, our proposed solution helped harmonise decision-making across different areas of the company.
\end{abstract}

Keywords: fuzzy logic; inventory management; production sequencing; systems engineering; cosmetics manufacturing; Brazil. 
Reference to this paper should be made as follows: Filho, M.M., Wanke, P.F. and Correa, H.L. (2016) 'Fuzzy logic in production sequencing: the case of a cosmetics manufacturer in Brazil', Int. J. Business Intelligence and Systems Engineering, Vol. 1, No. 1, pp.2-31.

Biographical notes: Mario Mannarino Filho holds a Master of Sciences in Business Administration (COPPEAD) and Bachelor in Economic Sciences (IBMEC/RJ). He works for a consulting company focused on business process management (BPM) and governance, risk and compliance (GRC).

Peter F. Wanke is an Associate Professor of Logistics and Supply Chain Management at COPPEAD Business School (Federal University of Rio de Janeiro) and publishes systematically on these subjects in international peer-reviewed journals.

Henrique L. Correa is a Professor of Operations Management at Crummer GSB and holds Visiting Professor appointments in a number of institutions in Latin America and Europe. He has numerous academic articles and books published in the fields of operations and supply chain management.

\section{Introduction}

Consumers' growing demand for new and varied products has posed increasing complexity and challenges to companies. Increased complexity requires that managers seek new ways to address operational issues. One such issue is production sequencing.

Production sequencing is a major activity that directly affects the performance of manufacturing firms (Stoop and Wiers, 1996). Due to the importance and impact of sequencing techniques on production performance, researchers have worked for decades on their development (Kathawala and Allen, 1993); however, few applications have been successful in practice (Stoop and Wiers, 1996).

Most manufacturing systems operate in dynamic environments (Ouelhadj and Petrovic, 2009), which is perhaps the reason why the successful practical application of sequencing techniques is relatively rare. The initial focus of studies on sequencing was to create feasible production sequences, that is sequencing that could actually be implemented in manufacturing plants (Kathawala and Allen, 1993); however, in a dynamic environment, a production sequence can frequently become infeasible because of changes in the environment (e.g., equipment breakdowns). And even when a certain sequence is feasible, if it does not take into account changes for e.g., in demand it will tend to have worse results than if it had taken those into consideration.

This characteristic helps understand the gap between theory and practice in this area of study. Manufacturing systems tend not only to be dynamic, but also to have a high degree of complexity. Sequencing techniques developed in the literature however tend to be sometimes excessively simplified versions of reality (Stoop and Wiers, 1996).

One approach that can help researchers and practitioners deal with the complexity of systems is fuzzy logic (McNeil and Thro, 1994; Klir and Yuan, 1995; Kasabov, 1998; Ross, 2004; Lee, 2005). The first practical use of fuzzy logic is usually attributed to 
(Mamdani and Assilian, 1975). The author developed a production control system based on fuzzy logic principles. Despite the numerous fields of application of fuzzy logic, possibly the most significant and successful ones focused on control problems (Bilkay et al., 2004; Ross, 2004).

According to Karwowski and Evans (1986), the sequencing of production is one activity to which fuzzy logic can potentially be applied mainly because it considers and enhances the expert's knowledge of the environment in question. If mediated by the knowledge of experts, fuzzy logic can assist - in capturing the complexities and uncertainties of production systems and their environment. Thus, when fuzzy logic is used in the development of a model to manage, for example, production sequencing, such model can take into account important aspects of the realities actually faced by the system; in contrast, traditional modelling techniques tend to simplify them out.

A production control system based on fuzzy logic also has the ability to overcome computational difficulties and costs related to the optimisation of stochastic techniques-based sequencing (Dubois et al., 2003; Bilkay et al., 2004). In addition to being able to capture (at least part of) the complexity of a production system, a control tool based on fuzzy logic has also the potential to allow for greater dynamism in decision making (for e.g., with easier and faster re-sequencing in response to environmental changes whenever needed).

The application of fuzzy logic in sequencing is a growing field of interest in the literature, but it has not yet been explored in practice as much as one could expect. More specifically in relation to the environment studied in this paper - namely, that of cosmetics manufacturing - no study was found in the literature that addressed production sequencing. We intend this paper to contribute both - to advance the study and in the development of a fuzzy logic application to production sequencing. Also, to help close the theory-practice gap in the field, by presenting a real life problem addressed by a fuzzy logic based decision support tool in a real cosmetics manufacturing plant.

This paper is structured in five sections including Section 1: introduction. Section 2 presents a statement of our objectives, research question and a review of the literature. The aim here is to discuss the concepts of production sequencing (dynamic and knowledge-based) and fuzzy logic (uncertainty, fuzzy systems and fuzzy logic in production sequencing). Section 3 presents the methodology we used. Section 4 presents and discusses the research results, and finally, Section 5 brings our main findings and conclusions, including implications, limitations, and directions for further research.

\section{Objectives, research question and a brief literature review}

Our goal in this research is to provide a cosmetics manufacturing operation with a way to reduce loss of sales due to stock-outs and to increase the amount of items without loss of sales through the application of fuzzy logic. The achievement of such two goals should help the cosmetics manufacturer better achieve its sales goals and as a consequence, to improve its overall product demand fulfilment.

Our research question therefore is basically:

Is it possible to reduce the loss of sales caused by stock-outs while simultaneously achieving sales goals by using a fuzzy logic-based tool in the analysed production unit? 
Supporting literature was surveyed to help us address our research question. This section discusses the literature on production sequencing and fuzzy logic. The main findings of our survey of the existing literature are presented below.

\subsection{Production sequencing}

In the business context, Slack et al. (2007) and Correa and Correa (2012) consider sequencing as an integral part of the overall activity of production planning and control in manufacturing organisations. The border that separates sequencing from other production planning and control sub-activities varies from case to case, as do the interactions with other functions within a business (Pinedo, 2001). Sequencing is one of the important factors affecting production performance together with other ones such as the definition and positioning of inventory levels, demand forecasting, and the management of resources (including the levels of efficiency, reliability and quality they can deliver) (Pinedo, 2001).

The literature contains numerous methods of sequencing to handle various types of production problems and contexts. In each case, the most suitable method will depend upon its effectiveness vis-à-vis the desired goals and objectives. Operations performance objectives - such as dependability, cost, flexibility, quality and speed - can generically serve as a basis for assessing the effectiveness of a particular sequencing method.

One of the pioneer studies in this area, Conway et al. (1967) describes the sequencing problem as comprised of four groups of information pieces:

1 the jobs and individual operations to be processed

2 the number and types of machines that comprise the shop

3 the sequencing disciplines that define the manner in which assignments (of operations to machines) are made

4 the criteria by which a sequencing logic (or discipline) will be evaluated.

\subsubsection{Dynamic sequencing}

A distinction between sequencing techniques that is relevant, according to literature, is whether a certain sequencing technique is static or dynamic in nature. In the static case the information required to create a feasible (however not necessarily optimal) sequence is known before the first job is processed. In this case the sequencing and the execution of the sequence are considered consecutively. A sequencing problem is called dynamic if the sequence is being constructed (and subsequently reconstructed) while orders are entering the shop. This is the case when the total demand or production-relevant parameters are not completely known in advance but such information becomes available during production. For each type of sequencing - static and dynamic, different methods are usually deployed (Conway et al., 1967).

In real complex manufacturing environments it is very unlikely the information required to create a feasible sequence is known before the first job is processed. It is all too frequent that conditions change and unpredicted events happen as orders come in. 
Actions then need to be taken dynamically to address them; this tends to happen in the form of re-sequencing. For this reason dynamic sequencing techniques are usually a better approach for the development of sequencing tools to be used in practice. Our approach in this paper falls into the dynamic sequencing category.

There are two main questions regarding re-sequencing: how to re-sequence and when to re-sequence. To answer the first question, two main strategies are available:

1 to come up with a 'repair' for the production sequence

2 to come up with the complete re-sequencing of production

(Ouelhadj and Petrovic, 2009).

Sequence repair is usually about local adjustments while complete re-sequencing involves a totally reformulated sequence. In practice, sequence repair is the most commonly used approach when dealing with re-sequencing (Abumaizar and Svestka, 1997).

As per the second question: when to re-sequence, Ouelhadj and Petrovic (2009) point to three main strategies: periodic re-sequencing, event-driven re-sequencing, and hybrid re-sequencing. Periodic re-sequencing performs re-sequencing at regular intervals, i.e., the sequence is revised for the next planning period. In event-driven re-sequencing, dynamic re-sequencing is triggered by relevant events, not by the passing of time. The hybrid strategy relies on some sort of combination of both periodic and event-driven re-sequencing.

\subsubsection{Knowledge-based systems}

According to Ouelhadj and Petrovic (2009), knowledge-based systems are those that focus on capturing the expertise or the experience of the expert in a specific domain and an inference mechanism is used to derive conclusions or recommendations regarding the corrective action to undertake. Kathawala and Allen (1993) consider that the purpose of knowledge-based systems is to fit the environment from which it was derived, and hence they are normally unsuitable for other realities. This characteristic does not, however, assume that knowledge-based systems are inflexible. The systems' flexibility derives from the incorporation of changes in the environmental aspects that shaped the system, such as the level of resources available.

Creating such a knowledge-based sequencing system may not be an easy task, and often the transfer of knowledge from the expert to the system may eventually become an obstacle to its development (Kathawala and Allen, 1993). One of the ways to deal with the capture and use of human expert knowledge by control systems is the use of fuzzy logic, which is discussed in more detail below.

\subsection{Fuzzy logic}

Fuzzy logic - or, more precisely, fuzzy set theory - was originally proposed by Zadeh (1965). The fuzzy logic approach has the ability to deal with the ambiguity (Lee, 2005) and vagueness (Klir and Folger 1988; Bergmann, 2008) of elements. As put by Zadeh (1965), a fuzzy set is a class of objects with a continuum of grades of membership. By admitting grades (degrees) of membership of an element to a set, this concept differs from classical set theory in which an element either does or does not belong to a group (Dubois and Prade, 1996; Kasabov, 1998; Ross, 2004; Bergmann, 2008). 
In fuzzy logic, the degree of membership of an element to a set is generally represented by a range from 0 to 1 , with 1 representing total belonging to a group and 0 the opposite; in this way, an element may belong to a set that represents it to a greater or lesser degree. This concept is also referred to as 'typicality', where not all members of a set are equally good representatives of it, some being more representative than others (Dubois and Prade, 1996). By eliminating the sharp boundaries between sets, fuzzy set theory introduces a way of dealing with the vagueness and imprecision of elements (Ross, 2004).

A membership function is an abstract notion that mathematically represents the degree to which an element belongs to a set (Klir and Yuan, 1995; Kasabov, 1998; Ross, 2004; Dubois, 2011). The membership function must be interpreted considering context, and its power to express the characteristics of a set must be sufficiently strong (Klir and Folger, 1988); therefore, the construction of a membership function is of critical importance (Ross, 2004). The construction of membership functions is discussed further in the section on fuzzy systems.

\subsubsection{Dealing with uncertainty}

Zadeh (1965) was not the first piece of research to introduce the concept of accepting and dealing with uncertainty in real world phenomena. For long, people have been thinking about aspects that are today part of fuzzy logic, such as degree of membership (or levels of similarity) of elements to sets and the insufficiency of traditional mathematics to handle the complexity and vagueness of the real world.

Important steps in this direction were taken by Max Black in his 1937 study, which considered the extent to which objects were members of a set (McNeill and Thro, 1994). A second early contribution worth mentioning is that by Abraham Kaplan and Hermann Schott in their 1951 study, which developed a theory of sets in which membership is a matter of degree. They incorporated in their study mathematical calculations present in classical set theory, such as intersection, union, complementation and subsets (Williamson, 1994). Later, in 1965, with a more elaborate mathematical framework, Zadeh (1965) developed, with ideas similar to Kaplan and Schott's, the theory of fuzzy sets (Williamson, 1994).

\subsubsection{Fuzzy systems}

One of the first practical uses of fuzzy logic was that by Mamdani and Assilian (1975), who applied it to develop a control system. Nowadays, fuzzy systems are used in a wide variety of situations and technologies, such as in the design and operation of consumer products (e.g., washing machines and cameras), in industrial controls (e.g., elevators), in large public systems (e.g., the subway) and in medical devices (e.g., cardiac pacemakers) (McNeill and Thro, 1994). Despite the numerous fields of application, one of the most significant and successful filed where fuzzy logic is used is control problems (Bilkay et al., 2004; Ross, 2004). One recent example is Rodger et al. (2014) who provides an interesting example of the use of fuzzy-logic in inventory control to reduce back orders of spare parts.

The use of fuzzy logic as a basis for modelling a production control system is justified by the complexity of the problem faced by production managers. Such complexity makes the use of conventional mathematical methods more problematic 
(Bilkay et al., 2004; Ross, 2004) or insufficient. The use of fuzzy logic to model production control systems is also justified by the ability of fuzzy logic to capture and apply the experience/knowledge of the human experts (e.g., the production system managers) (Verbruggen and Bruijn, 1997). The latter may constitute one of the main differences from a traditional production control system; in fuzzy logic decision making and action taking are derived from a rule base, usually developed from expert experience (Dubois and Prade, 1996).

Increased robustness and consistency in decision making is one of the advantages of using a fuzzy logic-based production control system over a conventional one. The literature lists the above and several other advantages such as: the ability to control and resolve situations too complex to analyse by conventional approaches; increased robustness; greater capacity to incorporate expert knowledge; and, the ability to incorporate more observed problem variables (McNeill and Thro, 1994; Lee, 2005).

\subsubsection{Fuzzy logic in production sequencing}

Production sequencing is one of the potential applications of fuzzy logic. According to Karwowski and Evans (1986), the experience and knowledge of the expert manager or decision maker in the environment in question are critical in production sequencing; thus, fuzzy logic would be a good tool to enhance the use of this knowledge in order to better solve the sequencing problem. Moreover, the information and parameters needed for decision making in the production environment are frequently imprecise.

Summarising, the complexity and uncertainty of a production environment make fuzzy logic an interesting heuristic technique to circumvent the difficulties and computational costs related to the optimisation of sequencing by traditional stochastic techniques (Dobois et al., 2003; Bilkay et al., 2004).

\section{Methodology}

The main identified problem that our case cosmetics producer was experiencing was the loss of sales due to lack of inventory of finished products available to its direct customers - or simply the 'stock-out cost' as referred to in this study. With the information obtained through the diagnosis performed and the devised theoretical framework, our main research question is 'Is it possible to reduce sales loss caused by stock-outs while simultaneously achieving unit sales goals by using a fuzzy logic-based tool in the analysed production unit?'

The sequencing of production at the factory in question was a long process that involved many areas of the company. The process started at the beginning of each month, involving different areas of headquarters and the factory, with the discussion of the master production plan of items to be produced. Evidently the plan must be consistent with the projected availability of raw materials, components and production capacity for that month.

The focus of our analysis was limited to practices relating to the (internal) Logistics department, in charge of production sequencing, scheduling and control. Specifically we decided to study better ways to support the production sequencing decisions at the plant, given its impact on the plant performance in terms of the variables we were interested in: sales loss, number of items without sales loss and achievement of sales targets. 


\subsection{Production sequencing}

The sequencing made by the Logistics team is the result of a set of priorities that are established for production. As any organisation, our cosmetics manufacturer has multiple objectives to be met, which in turn translate into metrics and indicators (such as those related to how well the company reaches its sales targets) which in turn are composed of variables.

Below are the variables used by the Logistics team for production sequencing decision making. We also provide descriptions of how they are used to generate the sequencing of items to be produced.

- Expected days of inventory. This is the main variable tracked by the managers of the company. Inventory days directly influence the company's level of service insofar as this indicator influences the availability of the item to the customer. This variable is also linked to the cost of stock-outs. This variable is calculated taking into account demand forecast and it indicates for how many days stock could fill expected demand.

- Stock-out cost. This is calculated from the marginal sales volume foregone due to the unavailability of a particular item. Stock-out cost is incurred if the item is not readily available for sale. Thus, expected demand does not influence this indicator, whereas actual demand does.

- Criticality of the item. This is a variable that encompasses certain subjective characteristics of items, such as strategic value to the company brand and complexity of production activities.

The above variables were used by the Logistics team as follows.

First, the items are ranked in an ascending order, based on expected days of inventory in a way that the first ranked item has the least expected days of inventory, and the last ranked item has the most expected days of inventory.

Second, if a tie break is needed, items with the same expected days of inventory are sub-ranked in a descending order based on their unit stock-out cost. So stock-out cost serves as the first tiebreaker in the definition of priority for sequencing.

Third, criticality is used as a second tiebreaker. Items with similar expected days of inventory AND similar stock-out costs, are then sub-ranked on a descending order taking into account criticality. Here characteristics such as whether the product is being launched and whether it has high production complexity can be used somewhat subjectively by the Logistics team to set priorities. According to team members, generally a product being launched will have a higher priority than a product with high production complexity. Items that have none of these characteristics will have neutral/normal priority in the tiebreak criterion (criticality).

\subsubsection{Proposed approach}

The approach proposed here is based on developing and testing a fuzzy inference system (in the form of a practical tool) that captures and uses the Logistics team knowledge and experience to support the generation and dynamic re-generation of more consistent and better production sequences. The developed fuzzy inference system will then be compared with the current practices of the company, in terms of the performance 
characteristics that the company uses to evaluate sequence performance by using simulation.

Fuzzy logic as a general approach was chosen because it can incorporate simultaneously multiple variables (see section on literature review), some stochastic elements and, information captured from the knowledge of experts via their utterances. The proposed system is largely based on variables that the company already uses some of them, in a subjective way: expected days of inventory, criticality, expected daily sales loss, and coefficient of variation of demand.

Expected days of inventory are calculated as follows:

$$
\text { Expected days of inventory }=\left(\frac{\text { Inventory }}{\text { Monthly demand forecast }}\right) \times 30
$$

Before we proceed it is important to define one important instrument in the operationalisation of fuzzy logic in inference and this is the membership function.

\subsubsection{Membership function}

A membership function for a fuzzy set $S$ on a domain $X$ is defined as $\mu_{\mathrm{S}}: \mathrm{X} \rightarrow[0,1]$, where each element of $X$ is mapped to a value between 0 and 1 . This value, called degree of membership, quantifies the grade of membership of the element in the domain $\mathrm{X}$ to the fuzzy set S. Membership functions allow for graphical representations of a fuzzy set. The $x$ axis represents a domain, for one example in our system, 'expected days of inventory' (see Figure 1), whereas the $y$ axis represents the degrees of membership in the $[0,1]$ interval. For example, in the membership function depicted in Figure 1, different values of 'expected days if inventory' on the $x$ axis are mapped to values between 0 and 1 on the $y$ axis, these representing the degree to which different 'expected days of inventory' are 'members' of the 'low' and 'very low' fuzzy sets. The higher the value on the $y$ axis the higher the degree of membership to the set, of the given value of 'expected days of inventory' for an item. Normally, simple functions are used to build membership functions because we are defining fuzzy concepts, so using more complex functions does not necessarily add more precision.

Membership functions were defined in our study by one of the authors facilitating a series of meetings of experienced Logistics team members involved with production sequencing in our cosmetics manufacturing with the aim of achieving consensus among team members as per how the functions should look like.

\subsubsection{Membership functions in our study}

\subsubsection{Expected days of inventory}

The membership function of expected days of inventory is represented in Figure 1. 
Figure 1 Membership function for expected days of inventory (see online version for colours)

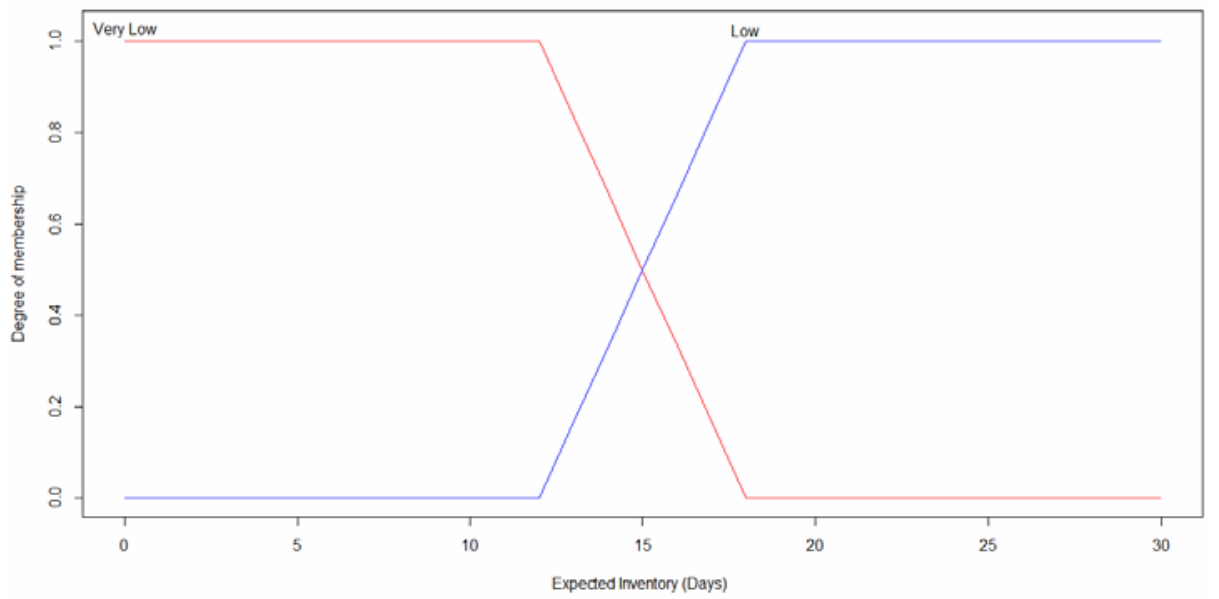

Source: Authors

\subsubsection{Criticality}

According to our experts, the criticality of an item can have the following values:

1 normal production complexity

2 high production complexity

3 product launch.

For the sake of simplicity, in the simulations that we will perform to evaluate the performance of different sequences will not include items that can have more than one classification, for example, by having high production complexity and also being a product launch. The membership function for criticality is represented in Figure 2.

Figure 2 Membership function for criticality (see online version for colours)

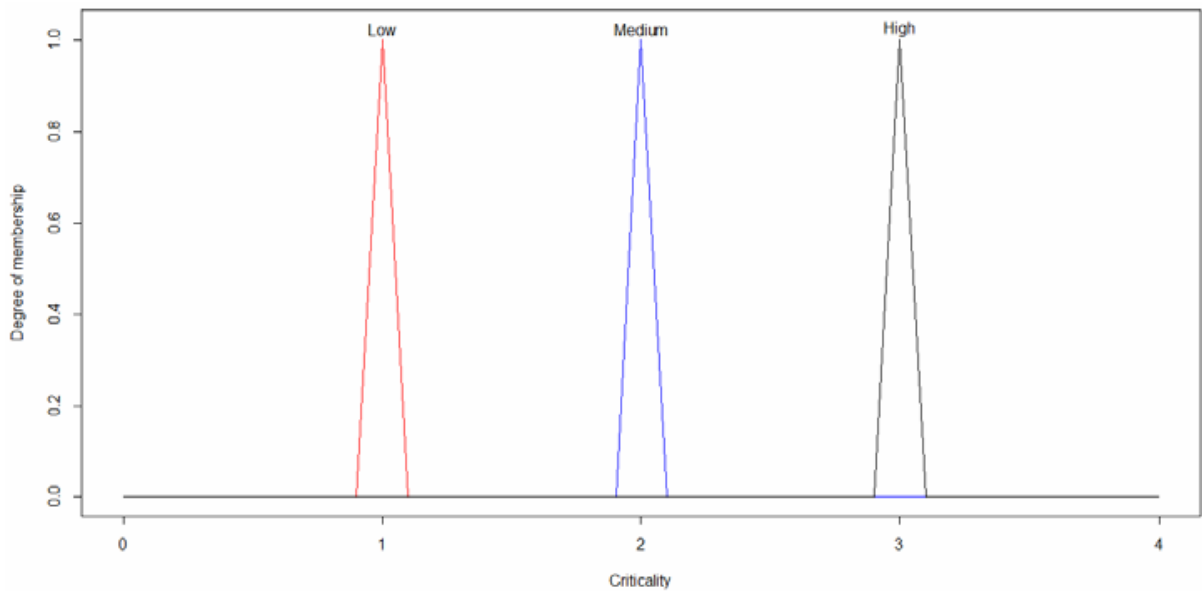

Source: Authors 


\subsubsection{Expected daily loss}

The expected daily loss is the measure used to represent the daily financial cost of the unavailability of an item. Unlike the stock-out cost used by the organisation, which represents how much the company is actually losing in sales because of a stock-out, the expected daily loss represents the daily cost of sales losses if the stock level were at zero.

The expected loss is measured daily in terms of Brazilian currency, the real, and is calculated as follows:

$$
\text { Expected daily loss }=\left\{\begin{aligned}
0, & \text { Inventory }=30 \\
\frac{(\text { Demand forecast }- \text { Inventory }) \times \text { Average price }}{30-\text { Expected days of inventory }}, & \text { Inventory }<30
\end{aligned}\right.
$$

The membership function for expected daily loss is represented in Figure 3, also obtained by consensus of our experts.

Figure 3 Membership function for daily expected loss (see online version for colours)

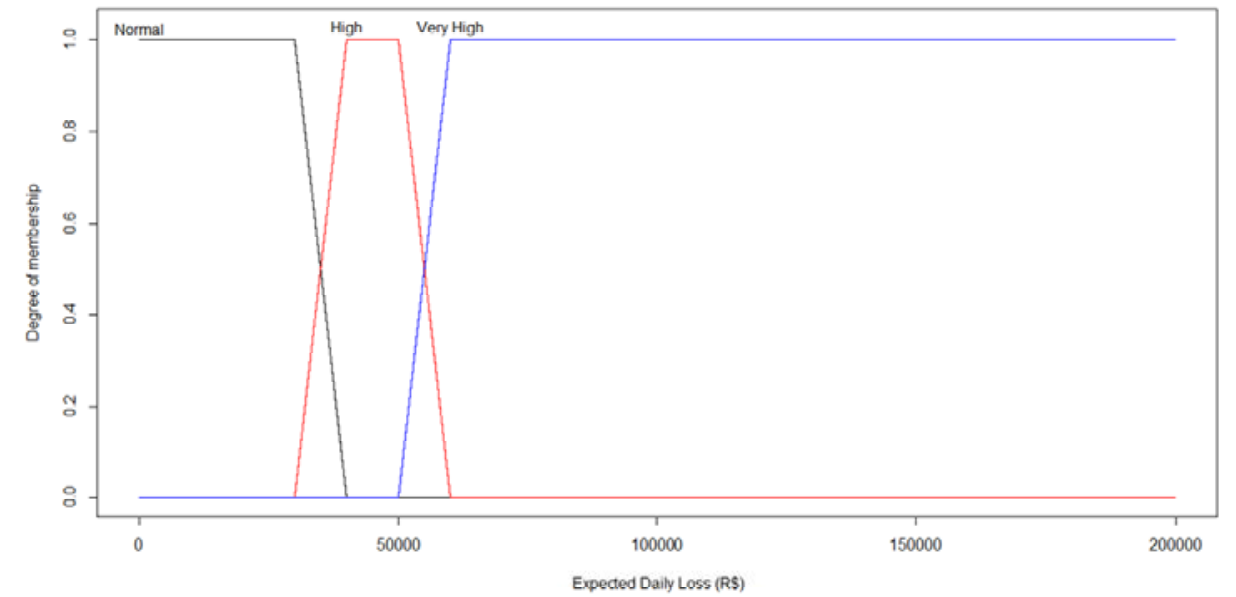

Source: Authors

\subsubsection{Demand coefficient of variation}

The coefficient of variation of demand is the measure that reflects the volatility of demand. The assortment of products offered by our cosmetics manufacturer is quite broad and is constantly being renewed. Because of this wide portfolio of products, the company has in the market both mature products with less volatile demand and, product launches, with a low degree of demand predictability. This particular characteristic of the products does not seem to have been taken into consideration by the Logistics team in their procedures for ranking items; however, we had several discussions with them arguing that, because expected demand will directly affect expected days of inventory, sequencing is indirectly affected by demand and its volatility. The experts agreed that this aspect was actually important and should be included in the considerations for the development of the system. 
As a result of the discussions with the experts, the coefficient of variation of demand was defined to be measured as a percentage, and its membership function is represented in Figure 4.

Figure 4 Membership function for coefficient of variation of demand (see online version for colours)



Source: Authors

Each item that the organisation has in its product portfolio is rated in terms of each of the four variables. The priorities are then established as a function of how the Logistics team perceives the urgency of production of each item based on the scores assigned to each in terms of the four above variables (expected days of inventory, criticality, daily sales loss and demand variation). There are six priority ratings: very low, low, medium, high, very high, and urgent. Figure 5 illustrates the membership function for priority.

Figure 5 Membership function for priority (see online version for colours)

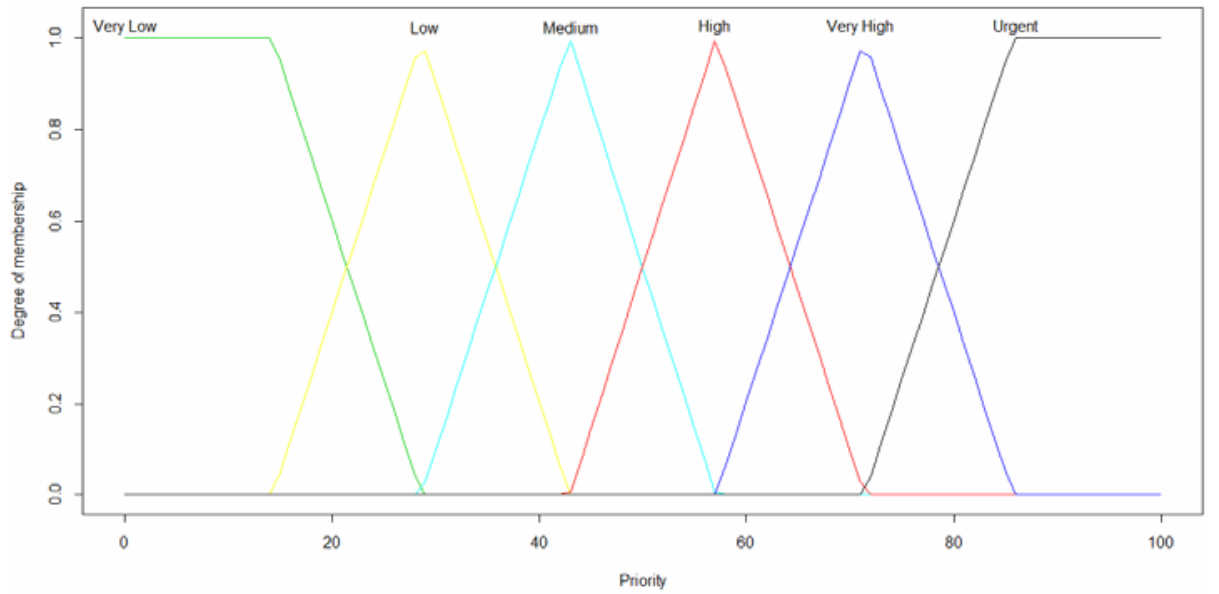

Source: Authors 
Thus, each item must fit into some priority level; and this fit will depend upon the combination of ratings in terms of the four previously described variables. In this study, the rationale behind the designation of item priorities is termed the 'Priority rules', which are listed in Table 1.

Table 1 Priority rules for sequencing the cosmetics manufacturer production

\begin{tabular}{|c|c|c|c|c|c|}
\hline Rule & $\begin{array}{c}\text { Expected } \\
\text { inventory days }\end{array}$ & $\begin{array}{l}\text { Expected } \\
\text { daily loss }\end{array}$ & $\begin{array}{c}\text { Demand variation } \\
\text { coefficient }\end{array}$ & Criticality & Priority \\
\hline 1 & Very low & Very high & High & High & Urgent \\
\hline 2 & Very low & Very high & High & Medium & Urgent \\
\hline 3 & Very low & Very high & High & Low & Urgent \\
\hline 4 & Very low & Very high & Medium & High & Urgent \\
\hline 5 & Very low & Very high & Medium & Medium & Urgent \\
\hline 6 & Very low & Very high & Medium & Low & Very high \\
\hline 7 & Very low & Very high & Low & High & Urgent \\
\hline 8 & Very low & Very high & Low & Medium & Very high \\
\hline 9 & Very low & Very high & Low & Low & High \\
\hline 10 & Very low & High & High & High & Very high \\
\hline 11 & Very low & High & High & Medium & Very high \\
\hline 12 & Very low & High & High & Low & Very high \\
\hline 13 & Very low & High & Medium & High & Very high \\
\hline 14 & Very low & High & Medium & Medium & Very high \\
\hline 15 & Very low & High & Medium & Low & High \\
\hline 16 & Very low & High & Low & High & Very high \\
\hline 17 & Very low & High & Low & Medium & High \\
\hline 18 & Very low & High & Low & Low & Medium \\
\hline 19 & Very low & Normal & High & High & High \\
\hline 20 & Very low & Normal & High & Medium & High \\
\hline 21 & Very low & Normal & High & Low & High \\
\hline 22 & Very low & Normal & Medium & High & High \\
\hline 23 & Very low & Normal & Medium & Medium & High \\
\hline 24 & Very low & Normal & Medium & Low & Medium \\
\hline 25 & Very low & Normal & Low & High & High \\
\hline 26 & Very low & Normal & Low & Medium & Medium \\
\hline 27 & Very low & Normal & Low & Low & Low \\
\hline 28 & Low & Very high & High & High & Medium \\
\hline 29 & Low & Very high & High & Medium & Medium \\
\hline 30 & Low & Very high & High & Low & Medium \\
\hline 31 & Low & Very high & Medium & High & Medium \\
\hline 32 & Low & Very high & Medium & Medium & Medium \\
\hline 33 & Low & Very high & Medium & Low & Low \\
\hline
\end{tabular}

Source: Authors 
Fuzzy logic in production sequencing

Table 1 Priority rules for sequencing the cosmetics manufacturer production (continued)

\begin{tabular}{|c|c|c|c|c|c|}
\hline Rule & $\begin{array}{c}\text { Expected } \\
\text { inventory days }\end{array}$ & $\begin{array}{l}\text { Expected } \\
\text { daily loss }\end{array}$ & $\begin{array}{c}\text { Demand variation } \\
\text { coefficient }\end{array}$ & Criticality & Priority \\
\hline 34 & Low & Very high & Low & High & Medium \\
\hline 35 & Low & Very high & Low & Medium & Low \\
\hline 36 & Low & Very high & Low & Low & Very low \\
\hline 37 & Low & High & High & High & Low \\
\hline 38 & Low & High & High & Medium & Low \\
\hline 39 & Low & High & High & Low & Low \\
\hline 40 & Low & High & Medium & High & Low \\
\hline 41 & Low & High & Medium & Medium & Low \\
\hline 42 & Low & High & Medium & Low & Very low \\
\hline 43 & Low & High & Low & High & Low \\
\hline 44 & Low & High & Low & Medium & Very low \\
\hline 45 & Low & High & Low & Low & Very low \\
\hline 46 & Low & Normal & High & High & Very low \\
\hline 47 & Low & Normal & High & Medium & Very low \\
\hline 48 & Low & Normal & High & Low & Very low \\
\hline 49 & Low & Normal & Medium & High & Very low \\
\hline 50 & Low & Normal & Medium & Medium & Very low \\
\hline 51 & Low & Normal & Medium & Low & Very low \\
\hline 52 & Low & Normal & Low & High & Very low \\
\hline 53 & Low & Normal & Low & Medium & Very low \\
\hline 54 & Low & Normal & Low & Low & Very low \\
\hline
\end{tabular}

Source: Authors

Both the membership functions and the priority rules were based on information obtained from Logistics team members and other actors within the organisation. The goal of our approach is not to create a mechanism that merely mimics the decision making of the experts within the organisation; rather, it aims to create a mechanism that is capable of handling the complexity encountered when evaluating alternative courses of action.

Our next step was to test the fuzzy-logic model developed and compare its results with those obtained by the company's current practices in sequencing production. We used simulation to do that.

\subsection{Simulation}

To test our model and compare its potential performance with that of the current way managers of the cosmetics manufacturer sequence production, we used FuzzyToolkitUoN (Knott et al., 2013), a software package designed for use in the R (R Core Team, 2014) software environment. The simulation was based on the Monte Carlo method. 


\subsubsection{Monte Carlo method}

In Monte-Carlo simulation, the value of a distributed parameter is selected by the generation of a random number, with the probability of a given value being determined by the association of random numbers to that variable. By repeating this process a large number of times, a picture of the distribution of the output random variable may be built up, from which estimates of the parameters of interest may be calculated, e.g., their mean, standard deviation, etc.

We considered that Monte Carlo simulation was the most suitable for our study because it enables the performance and robustness of the proposed model to be assessed by computation; indeed, it would be impractical to test the model in reality in a plausible number of times to reach minimally representative and reliable results. We performed 500 simulations for this study. In a study performed by Hamundu et al. (2012) in which concepts of fuzzy logic and Monte Carlo simulation are also used in developing a decision-support model, this was also the chosen number of times that the simulation would need to be run in order to minimise the possibility of errors arising from randomly generated variables.

Our simulation study was based on 90 items that should be sequenced according to defined production priorities. Each simulation run includes the two models that we are interested in comparing: our proposed fuzzy-logic based model and the current decision making model (a representation of the organisation's current practice). Random scenarios are then created based on assumptions for each of the variables used, which characterise each of the items to be sequenced in the simulation runs. In each simulation run, both models sequence the same input scenario; that is, they will work on the same 90 randomly generated items. The assumptions are as follows:

- Ninety diverse items.

- Each day, three items go into production, regardless of the number of units produced for each one, i.e., a total of 90 items are produced over the course of 30 days.

- Daily demand is evenly distributed throughout the simulated time period.

- An item is available to be sold as soon as its production is over - the production period includes the time for laboratory sample analysis and allocation at the distribution centre.

- The amount produced meets demand for the rest of the month independent of the demand volume.

- Unmet demand is lost.

- Expected days of inventory is a random variable uniformly distributed between 0 and 20 days.

- Monthly demand is a random variable uniformly distributed between 1,000 and 11,000 units.

- Average item price is a random variable uniformly distributed between $\mathrm{R} \$ 5.00$ and $\mathrm{R} \$ 50.00$.

- The coefficient of variation of demand is uniformly distributed between $10 \%$ and $90 \%$. 
- Items have a $20 \%$ chance of being a 'launch', a $5 \%$ chance of being 'high production complexity', and a 75\% chance of being 'normal'. (according to managers' estimates).

- Production lead time is uniformly distributed between seven and 20 days.

Each item will have randomly generated numbers associated to it within a pre-determined interval for each of the following variables: demand forecast (units); expected days of inventory (in days); average price ( $\mathrm{R} \$$ ); criticality (type); coefficient of variation of demand (\%); production time (days).

Once these variables have been generated, the other variables needed for the simulation can be calculated: inventory (units), demand variation (\%), expected loss (R\$), effective demand (units), potential daily loss ( $\$$ ), and days of inventory held (days).

The following are the calculations behind each of these variables:

- $\quad$ Inventory $=\frac{\text { Days of expected inventory }}{30} \times$ Demand forecast

- Expected daily loss $=\left\{\begin{array}{rr}0, & \text { Inventory }=30 \\ \frac{\text { Demand forecast }- \text { Average price }}{30-\text { Days of expected inventory }}, & \text { Inventory }<30\end{array}\right.$

- Demand variation $=$ Demand variation coefficient $\times$ Random variation factor

- $\quad$ Actual demand $=$ Demand forecast $\times(1+$ Demand variation $)$

- $\quad$ Days of inventory held $=\left(\frac{\text { Inventory }}{\text { Actual demand }}\right) \times 30$

- Potential daily loss $=\left\{\begin{aligned} 0, & \text { Inventory }=30 \\ \frac{\text { Actual demand }- \text { Inventory } \times \text { Average price }}{30-\text { Days of inventory held },} & \text { Inventory }<30\end{aligned}\right.$

- $\quad$ Available day $=$ Production time + Production day -1

- $\quad$ Days without sales $=$ Available day - Days of inventory held

- $\quad$ Stockout $\operatorname{cost}=$ Days without sales $\times$ Potential daily loss

- $\quad$ Sales $=$ Actual demand $\times\left(\frac{30-\text { Days without sales }}{30}\right)$

- $\quad$ Sales effectiveness $=\frac{\text { Sales }}{\text { Expected demand }}$

Note that both demand and inventory days have two aspects associated to them: expected and actual. In this simulation, demand forecast and expected inventory days are used as a base (along with coefficient of variation of demand and criticality) to simulate decision making. 
This is done because, in practice, decision making takes place at the beginning of the period - specifically at the beginning of the month - when managers do not know how actual demand will be, and thus decisions are made based on forecasts. For the calculation of the results, however, effective demand and actual days of inventory are used; this way we can assess, for each simulation run, how much of actual demand was met.

The variables used as inputs for the models are expected days of inventory, criticality, coefficient of variation of demand and expected daily loss. The output of the models is six fuzzy sets (very low, low, medium, high, very high and urgent). Items fall on some point of the continuum. A list with the priority of each item ranging from 0 to 100 is then defined, with 0 being the lowest priority and 100 the highest. These priorities are then used to sequence the items. If there are items with the same priority, the first tiebreaker is expected days of inventory (in ascending order); the second is criticality (in descending order); and the last is expected daily loss (in descending order). Readers should recall, that the lower the expected days in inventory, the higher the criticality, and the higher the expected daily loss, the higher production priority should be. The reverse is true for higher expected days in inventory, lower criticality, and lower expected daily loss.

In the case of the current model, there is no 'rule' for the establishment of priorities as there is one in the proposed model. Items are sequenced as follows: they are basically sorted by expected days of inventory (in ascending order). In case of items with 'too similar' expected days of inventory a tiebreaker is used: expected daily loss (in descending order). If a second tiebreaker is needed criticality is used to break the 'double' tie (in descending order). With respect to the first tiebreaker criterion, the item first has its expected daily loss classified by type ('Normal', 'High' and 'Launch') according to the interval in which it appears. This is to avoid that items with 'too similar' expected days of inventory are numerically treated as being substantially different for the purpose of defining production sequence.

The intervals are the same used in the membership function of Figure 3. In this case, an item that belongs to the 'Normal' set is classified as type 1, since an item that belongs to the 'High' set is classified as type 2, and the remaining ones are classified as type 3. An example of sequencing, encompassing several possible combinations, is found in Appendix 1.

\section{Discussion of results}

This section presents and discusses the results of the simulation performed for purposes of testing the proposed model in comparison to the current model. First, the main results are reviewed; then, the implications of the findings are discussed.

\subsection{Main results}

The results of the proposed model were generally superior to those of the current model. Table 2 summarises the results. 
Table 2 Summary of main results

\begin{tabular}{|c|c|c|c|c|}
\hline Variables & Average & $\begin{array}{l}\text { Standard } \\
\text { deviation }\end{array}$ & Biggest & Smallest \\
\hline \multicolumn{5}{|l|}{ Cost of stock-out (R\$) } \\
\hline Current model & $35,487,329$ & $4,354,764$ & $51,515,122$ & $24,357,558$ \\
\hline Proposed model & $30,809,254$ & $3,601,708$ & $43,506,664$ & $21,832,072$ \\
\hline Reduction in the stock-out cost & $4,678,075$ & 1,597612 & $13,055,011$ & $-309,336$ \\
\hline $\begin{array}{l}\text { Percentage of the reduction of } \\
\text { stock-out cost in relation to the } \\
\text { current model }\end{array}$ & $13 \%$ & $\begin{array}{c}3.7 \% \\
\text { points (p.p.) }\end{array}$ & $29 \%$ & $-1 \%$ \\
\hline \multicolumn{5}{|l|}{$\begin{array}{l}\text { Percentage of items without any } \\
\text { sales loss }\end{array}$} \\
\hline Current model & $4.6 \%$ & 2.2 p.p. & $13.3 \%$ & $0.0 \%$ \\
\hline Proposed model & $7.4 \%$ & 2.8 p.p. & $16.7 \%$ & $0.0 \%$ \\
\hline $\begin{array}{l}\text { Increase in the percentage of } \\
\text { items without loss of sales }\end{array}$ & 3.8 p.p. & 1.7 p.p & 8.9 p.p. & -2.2 p.p. \\
\hline \multicolumn{5}{|l|}{ Percentage of Sales Achievement } \\
\hline Current model & $43.3 \%$ & 3.1 p.p. & $53.9 \%$ & $33.9 \%$ \\
\hline Proposed model & $46.4 \%$ & 3.3 p.p. & $56.2 \%$ & $37.9 \%$ \\
\hline $\begin{array}{l}\text { Increase in the percentage of sales } \\
\text { goal achievement }\end{array}$ & 3.1 p.p. & 1.6 p.p. & 12.3 p.p. & -2.4 p.p. \\
\hline
\end{tabular}

Source: Authors

The proposed model seem to positively answer our main research question quite well, by displaying better results not only in relation to the cost of stock-outs, but also in relation to the number of items without loss of sales and to the achievement of unit sales goals. More specifically in relation to the cost of stock-outs, the model showed good robustness in that this aspect was found to be reduced in almost all of the 500 simulation runs. Table 3 summarises the frequency with which the difference in results was positive, neutral or negative between models.

Table 3 Summary of frequencies of differences between models (\%)

\begin{tabular}{lccc}
\hline Variables & Positive & Neutral & Negative \\
\hline Reduction in the cost of stock-out & 499 & 0 & 1 \\
Increase in the percentage of items without loss of sales & 459 & 39 & 2 \\
Increase in the percentage of sales goals achievement & 488 & 0 & 12 \\
\hline
\end{tabular}

Source: Authors

\subsubsection{Cost of stock-outs}

Table 4 shows the descriptive statistics of the resulting data relating to the cost of stock-outs for both models. Graphs 1 and 2 show the improved performance of the proposed model in comparison to the current model through box plots (Figure 6) and superimposed density curves (Figure 7). 
Table 4 Descriptive statistics of boxplots of models (in R \$ million)

\begin{tabular}{lcccccc}
\hline Model & Minimum & 1st Quartile & Median & Average & 3rd Quartile & Maximum \\
\hline Current & 24.36 & 32.25 & 35.36 & 35.49 & 38.43 & 51.52 \\
Proposed & 21.83 & 28.33 & 30.65 & 30.81 & 33.36 & 43.51 \\
\hline
\end{tabular}

Source: Authors

Figure 6 Boxplots of current and proposed models

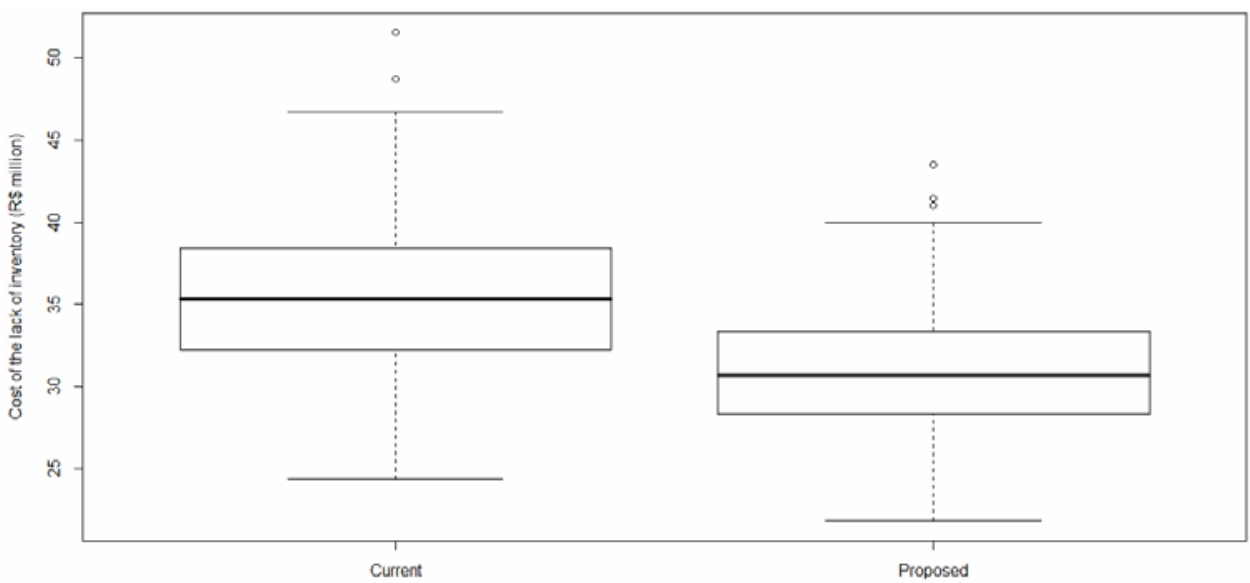

Source: Authors

Figure 7 Density curves of cost of stock-outs for the models (bandwidth of 2) (see online version for colours)

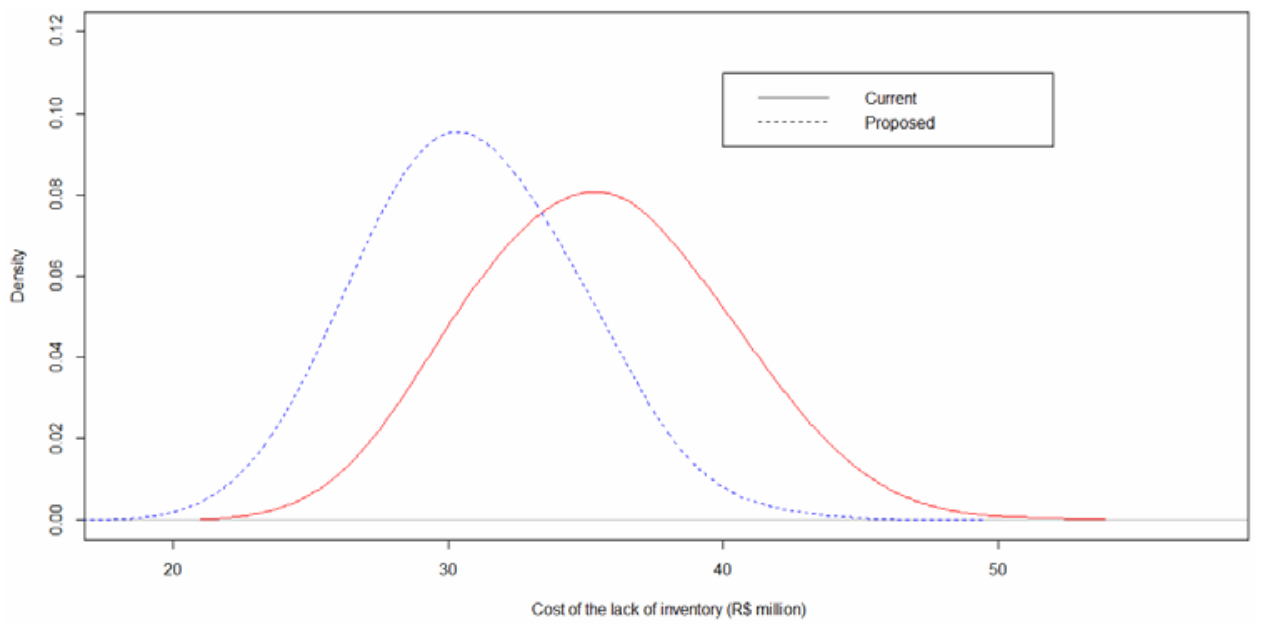

Source: Authors 


\subsubsection{Items without sales loss}

Figure 8 shows the superimposed density curves of both models - current and proposed, regarding the results of the percentage of items without loss of sales; Table 5 shows the distribution of relative and cumulative frequencies. It is important to note that the proposed model not only demonstrated improved average performance, but also achieved higher levels of revenue; the current model was able to prevent a maximum of $13.3 \%$ of the items from losing sales, while the proposed model achieved $16.7 \%$.

Figure 8 Density curves for percentage of items without sales loss (see online version for colours)

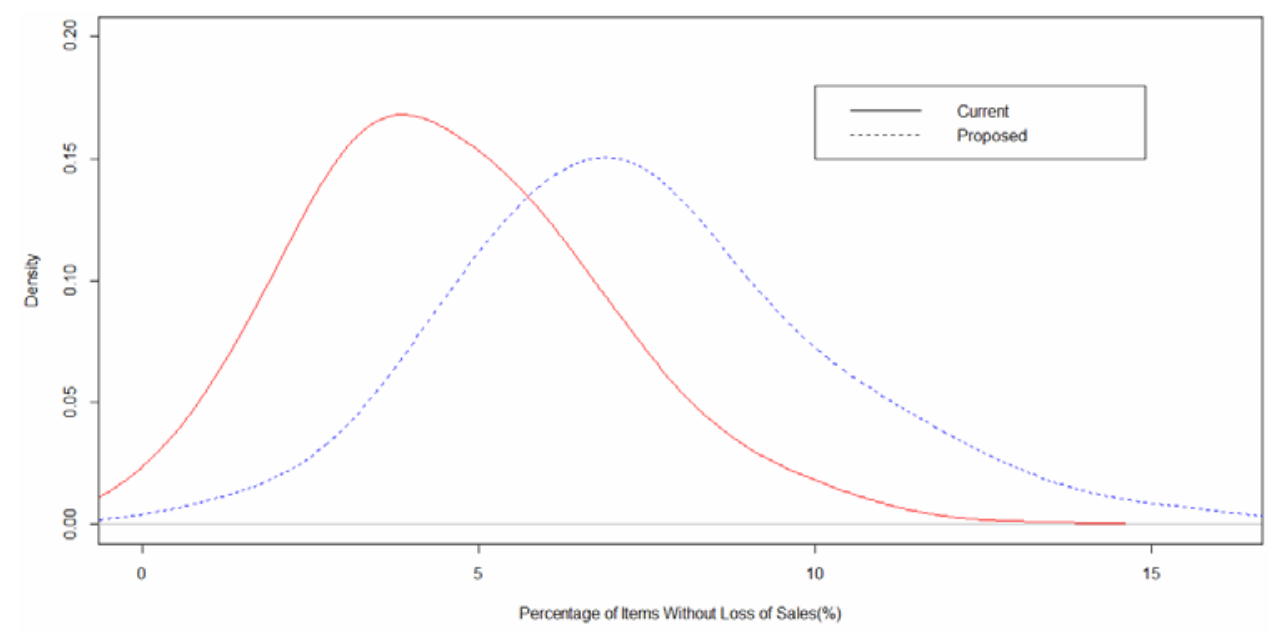

Source: Authors

Regarding Table 5, a significant characteristic of the frequency distribution of the percentage of items without loss of sales is that approximately $80 \%$ of the frequency of the results of the current model are situated in the range between $2.2 \%$ and $6.7 \%$, whereas approximately $80 \%$ of the frequency of the results of the proposed model are situated in the range between $4.4 \%$ and $10.0 \%$, as highlighted in the table itself.

Table 5 Frequency distribution of percentage of items without sales loss

\begin{tabular}{lccccc}
\hline Variable & \multicolumn{2}{c}{ Current model } & & \multicolumn{2}{c}{ Proposed model } \\
\cline { 1 - 2 } \cline { 5 - 6 } $\begin{array}{l}\text { Percentage of items without loss } \\
\text { of sales }\end{array}$ & Relative & Accumulated & & Relative & Accumulated \\
\cline { 1 - 2 } $0.0 \%$ & $1.6 \%$ & $1.6 \%$ & & $0.2 \%$ & $0.2 \%$ \\
$1.1 \%$ & $5.8 \%$ & $\mathbf{7 . 4 \%}$ & & $1.2 \%$ & $1.4 \%$ \\
$2.2 \%$ & $\mathbf{1 2 . 4 \%}$ & $\mathbf{1 9 . 8} \%$ & & $1.8 \%$ & $3.2 \%$ \\
$3.3 \%$ & $\mathbf{2 2 . 6 \%}$ & $\mathbf{4 2 . 4 \%}$ & & $4.2 \%$ & $7.4 \%$ \\
$4.4 \%$ & $\mathbf{1 7 . 6 \%}$ & $60.0 \%$ & & $\mathbf{1 0 . 6} \%$ & $18.0 \%$ \\
$5.6 \%$ & $\mathbf{1 7 . 0} \%$ & $77.0 \%$ & & $\mathbf{1 5 . 2} \%$ & $33.2 \%$ \\
$6.7 \%$ & $\mathbf{1 1 . 2 \%}$ & $88.2 \%$ & & $\mathbf{1 8 . 2} \%$ & $51.4 \%$ \\
\hline
\end{tabular}

Source: Author 
Table 5 Frequency distribution of percentage of items without sales loss (continued)

\begin{tabular}{lccccc}
\hline Variable & \multicolumn{2}{c}{ Current model } & & \multicolumn{2}{c}{ Proposed model } \\
\cline { 1 - 2 } \cline { 5 - 6 } $\begin{array}{l}\text { Percentage of items without loss } \\
\text { of sales }\end{array}$ & Relative & Accumulated & & Relative & Accumulated \\
\hline $7.8 \%$ & $6.0 \%$ & $94.2 \%$ & & $\mathbf{1 7 . 2 \%}$ & $68.6 \%$ \\
$8.9 \%$ & $3.0 \%$ & $97.2 \%$ & & $\mathbf{1 1 . 0 \%}$ & $79.6 \%$ \\
$10.0 \%$ & $2.0 \%$ & $99.2 \%$ & & $\mathbf{7 . 2 \%}$ & $86.8 \%$ \\
$11.1 \%$ & $0.6 \%$ & $99.8 \%$ & & $5.8 \%$ & $92.6 \%$ \\
$12.2 \%$ & $0.0 \%$ & $99.8 \%$ & & $3.4 \%$ & $96.0 \%$ \\
$13.3 \%$ & $0.2 \%$ & $100.0 \%$ & & $2.0 \%$ & $98.0 \%$ \\
$14.4 \%$ & $0.0 \%$ & $100.0 \%$ & & $0.8 \%$ & $98.8 \%$ \\
$15.6 \%$ & $0.0 \%$ & $100.0 \%$ & & $1.0 \%$ & $99.8 \%$ \\
$16.7 \%$ & $0.0 \%$ & $100.0 \%$ & & $0.2 \%$ & $100.0 \%$ \\
\hline
\end{tabular}

Source: Author

Table 6 illustrates the frequency that each level of criticality of the items showed without sales loss. The highest frequency of items with criticality level 3 and lowest frequency of items with criticality level 1 and 2 demonstrate that the proposed model better reflects the different preferences of the organisation in terms of different levels of criticality.

Table 6 Frequency of each level of criticality in items without sales loss

\begin{tabular}{lccccc}
\hline Variable & \multicolumn{2}{c}{ Current model } & & \multicolumn{2}{c}{ Proposed model } \\
\cline { 1 - 2 } \cline { 5 - 6 } Criticality & $\begin{array}{c}\text { Absolute } \\
\text { frequency }\end{array}$ & $\begin{array}{c}\text { Relative } \\
\text { frequency }\end{array}$ & & $\begin{array}{c}\text { Absolute } \\
\text { frequency }\end{array}$ & $\begin{array}{c}\text { Relative } \\
\text { frequency }\end{array}$ \\
\hline $\begin{array}{l}\text { Complex } \\
\text { production }\end{array}$ & 96 & $4.6 \%$ & & 135 & $3.9 \%$ \\
$\begin{array}{l}\text { Normal } \\
\text { Launch }\end{array}$ & 1,575 & $75.8 \%$ & & 2,541 & $74.3 \%$ \\
\hline
\end{tabular}

Source: Authors

\subsubsection{Achievement of sales goals}

Figure 9 illustrates superimposed density curves of the two models in terms of the results of percentage of sales goals achieved.

\subsubsection{Correlations}

An important aspect of the proposed model is that, in terms of reducing the cost of stockouts, it tends to be more efficient than the current model to the extent that the average 'days of inventory' (both expected and actual) is smaller and the average of variation of the demand is larger. In other words, the more critical the situation with respect to inventory levels and the more adverse the scenario in relation to demand, the more the proposed model will tend to provide a better solution than the current model. This correlation and the other correlations between key variables contained in the simulation are shown in Table 7. The meanings of the acronyms in Table 7 are listed in Table 8. 
Figure 9 Density curves of percentages of sales goals achieved (see online version for colours)

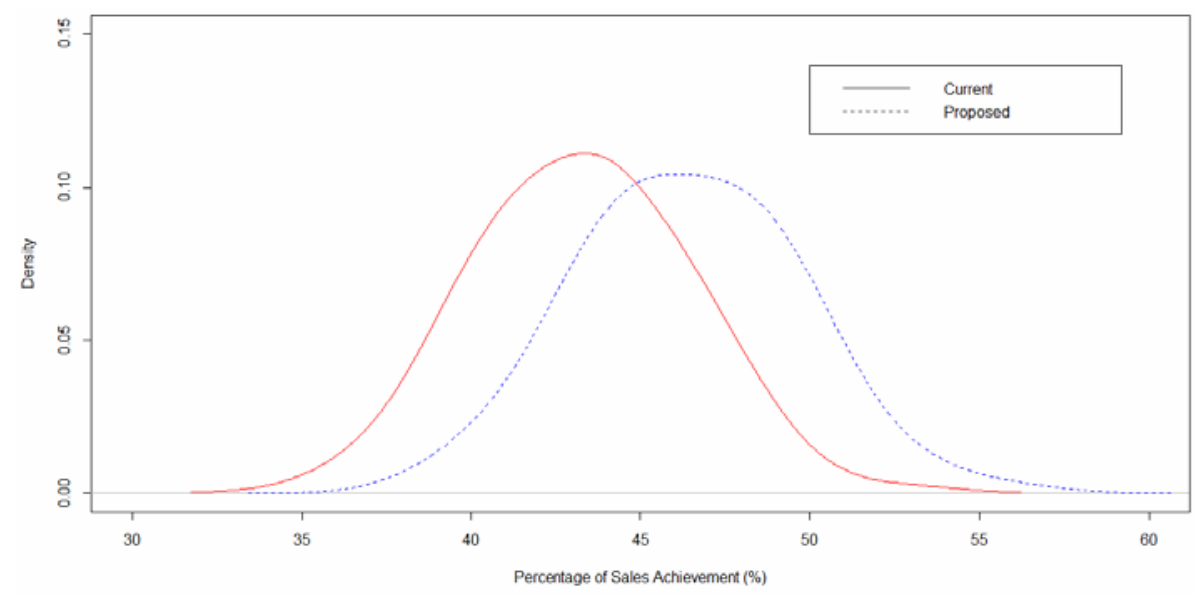

Source: Authors

Table 7 Correlations coefficients between variables

\begin{tabular}{lccccccccccc}
\hline & $R C F$ & $A P I S P V$ & $A P A V$ & $M D E E$ & $M P D E$ & $M C$ & MCVD & MDER & MPDP & MVD & MTP \\
\hline RCF & 1.00 & -0.08 & 0.78 & -0.15 & 0.43 & 0.10 & 0.08 & -0.18 & 0.55 & 0.17 & 0.02 \\
APISPV & -0.08 & 1.00 & -0.17 & 0.07 & 0.02 & 0.04 & 0.00 & 0.14 & -0.08 & -0.16 & -0.18 \\
APAV & 0.78 & -0.17 & 1.00 & -0.11 & 0.16 & 0.03 & 0.02 & -0.21 & 0.32 & 0.18 & 0.08 \\
MDEE & -0.15 & 0.07 & -0.11 & 1.00 & 0.07 & -0.10 & 0.03 & 0.69 & 0.05 & 0.02 & -0.10 \\
MPDE & 0.43 & 0.02 & 0.16 & 0.07 & 1.00 & 0.03 & 0.10 & 0.12 & 0.87 & -0.06 & 0.01 \\
MC & 0.10 & 0.04 & 0.03 & -0.10 & 0.03 & 1.00 & -0.03 & -0.08 & 0.06 & 0.02 & -0.03 \\
MCVD & 0.08 & 0.00 & 0.02 & 0.03 & 0.10 & -0.03 & 1.00 & 0.15 & 0.07 & 0.00 & -0.04 \\
MDER & -0.18 & 0.14 & -0.21 & 0.69 & 0.12 & -0.08 & 0.15 & 1.00 & -0.11 & -0.52 & -0.10 \\
MPDP & 0.55 & -0.08 & 0.32 & 0.05 & 0.87 & 0.06 & 0.07 & -0.11 & 1.00 & 0.33 & 0.02 \\
MVD & 0.17 & -0.16 & 0.18 & 0.02 & -0.06 & 0.02 & 0.00 & -0.52 & 0.33 & 1.00 & 0.01 \\
MTP & 0.02 & -0.18 & 0.08 & -0.10 & 0.01 & -0.03 & -0.04 & -0.10 & 0.02 & 0.01 & 1.00 \\
\hline
\end{tabular}

Table 8 Meaning of acronyms in Table 7

\begin{tabular}{ll}
\hline Acronym & Meaning \\
\hline RCF & Reduction in the cost of stock-out \\
APISPV & Increase in the percentage items without loss of sales \\
APAV & Increase in the percentage of sales achievement \\
MDEE & Average expected inventory days \\
MPDE & Average expected daily loss \\
MC & Average criticality \\
MCVD & Average demand variation coefficient \\
MDER & Average performed inventory days \\
MPDP & Average potential daily loss \\
MVD & Average demand variation \\
MTP & Average production time \\
\hline
\end{tabular}




\subsection{Discussion of results}

The proposed model proved to be a good alternative to improve the practice of the surveyed organisation with respect to the sequencing of production. Not only was it demonstrably more efficient the more adverse and unfavourable the scenario faced by the company is in terms of various parameters, but other aspects inherent in the proposed model also contribute to improving organisational practices.

First, the model proved to be a satisfactory heuristic approach for addressing the problem in question. Once the problem had been modelled, the time required to feed the system with the data for decision making was relatively short. This translates into much quicker decision-making, since the software tool that was built to operationalise the proposed model generates the priorities almost instantly when run. In addition, it takes into account uncertainties of the environment in which the organisation operates; hence generating better sequences upfront, thereby not requiring as many re-sequencing exercises as the current model does.

This characteristic is an important one because production sequencing can require a great deal of management effort, as in the case of our case organisation, in which the sequencing of production, as a whole, pervades much of the organisation. Thus, the fewer the modifications to the original plan, the better.

A second point relates to the flexibility of the model, as discussed by Kathawala and Allen (1993). An important feature of a system such as the one developed in this study is that it is highly flexible within the context in which it was developed. In order for the model to prioritise, for example, the objective of increasing the number of items without sales loss, it is sufficient to configure the priority rules so that this objective is prioritised in the inferences made by the model.

Furthermore, the model can also incorporate new variables that for some reason may start to have greater influence in the sequencing decision-making process. An example could be the probability of raw material stock-out.

A third point, also related to the flexibility of the model regards the links between different areas of the organisation, a problem addressed by Kreipl and Pinedo (2004). The flexibility of the model allows it to incorporate - myriad complexities notwithstanding the many variables that influence decision-making vis-à-vis production sequencing. Thus, in contrast to the models of production sequencing that focus only on the optimisation of machine resource allocation (according to the generic structure presented by Conway et al., 1967), the proposed model includes variables - and can include others - of a broader scope within the organisation. Hence, the proposed model also helps to break down silos within the organisation, resulting in more systemic decision-making.

\section{Conclusions}

The paper aimed to develop a way to improve practices of the organisation we analysed, specifically in relation to its production planning and control. After initial rounds of enquiry to identify specific problems we decided that our research would specifically target the activity of production sequencing, thus defining our research scope and focus.

We noted that uncertainties such as demand uncertainty directly affects the company's performance and can significantly increase the complexity of its decision making. In order to help the organisation improve the activity of sequencing and the 
organisation's ability to fulfil demand for its products, a sequencing tool based on fuzzy logic was developed.

Fuzzy logic has proven to be an effective alternative approach to support decision making in an environment of high complexity and uncertainty. With features that allow the capturing of knowledge of experts in the organisation, fuzzy logic was used to create a decision support tool that incorporates the complexities faced by the company.

After we developed the decision support tool, we used simulation to compare the two models - current and proposed. Variables related to demand, inventory, production time, and criticality of items, among others, were used to generate production sequences. Whereas the current model is based on the company's current decision-making, the proposed model also includes a measure of demand variation, thereby incorporating its potential impact on decision making.

The result of the simulations satisfactorily addressed the research questions. In all simulations, the sequencing tool generated sequences that reduced the overall cost of stock-outs. On average, there was a $13 \%$ reduction in the cost of stock-outs in the proposed model as compared with the current model. Moreover, there was an average increase of $2.8 \%$ in the number of items that did not experience lost sales due to stock-outs. In relation to the achievement of sales goals, in units, there was an average improvement of $3.1 \%$.

Additionally, the proposed model has inherent features that contribute to improving practices. First, the decision support tool developed enables the organisation to make decision-making more dynamic and agile, because it tends to reduce both the need for re-sequencing and the time required to make a decision.

Also, the flexibility of the proposed approach makes easily customised to better fit the context of its application. Thus, it is possible to modify the decision-making rules in order to reach different results, as well as to insert additional variables that can potentially influence the problem under study.

Another advantage of said flexibility is that it allows the proposed model to include the various variables that influence decision-making with respect to the sequencing of production - not just those relating to the factory floor, but all of those that somehow should influence the production sequencing activity - thus expanding the scope of analysis to create a more inclusive and systemic decision making environment involving different areas of the company.

\subsection{Implications of the study}

This study has implications to both theory and practice. First, Ouelhadj and Petrovic (2009) and several other authors, including MacCarthy and Liu (1993), Shukla and Chen (1996), and Cowling and Johansson (2002) have warned about the unhealthy gap that exists between the theory and practice of sequencing in the extant literature. This study bridges this gap by using a theoretical development (fuzzy-logic) to resolve a real-life problem. We have not set off to find an application for fuzzy logic. We identified a reallife problem faced by a real-life company (a cosmetics manufacturer in Brazil) and then we searched for a robust and appropriate method, backed by one theoretical approach to come about resolving it. The most evident implication to practice though is the possibility that practitioners facing challenging and complex production sequencing problems use this article to evaluate whether our general proposed approach to generating production 
sequences can be adapted to fit their needs. From our experience, fuzzy logic theory is not usually known by practitioners and hence they may never think about its practical use if a paper like this does not give them the opportunity to see it in use in a real setting. We tried to keep the language simple and the article readable by non-academics so that this objective could be achieved.

\subsection{Limitations of the research}

Our research case company is a real-life cosmetics manufacturer and we specifically developed a fuzzy-logic-based sequencing tool to improve their specific decision making. It is important to highlight the fact that the variables taken into account as influential in the generation of production sequences for the case company are specific for the company and we are not suggesting that they are directly used in other cases. Each case in which researchers or practitioners decide to use the general method that we propose here will have to go through a thorough analysis of their specific influential variables to be included. The same applies to the membership functions that we used. Consistent with one of the tenets of the use of fuzzy-logic, we identified membership functions by interviewing and discussing with actual decision makers to come up with the membership functions we used in this case. Once again, we do not make any suggestion that the functions we used here are also recommended to be used in other cases (although they evidently might be).

\subsection{Directions for further research}

In our research we propose a method for developing sequencing systems for a production unit using fuzzy logic; however we focused on the real problem that one specific cosmetics manufacturer was facing and by comparing our system's performance with the way the company managers were used to defining their production sequences we demonstrated remarkable improvement in a set of pre-defined performance metrics that are relevant to that particular situation. We believe that the higher the level of complexity faced by the production operation analysed the more our approach will be superior to more traditional approaches. However this is just a hypothesis that we can formulate based on our research. Further research would have to be performed to test that hypothesis.

We also included the consideration of demand variation as an important variable in the generation of production sequences in the cosmetics manufacturer with good results. The case company did not use to include demand variation when generating sequences. There is also great opportunities for researchers to try and identify other variables that might be of particular relevance for production sequencing and the impact on performance of their inclusion. This would help predict the impact of the inclusion of certain variables in production sequencing problems. In a recent paper, Rodger (2014) for instance used fuzzy-logic to analyse the influence of variables such as unit price, ordered quantity and stock on the performance of items in terms of backorder performance. These types of studies can help advance our general understanding of intervening variables in production and supply chain performance.

We would also suggest that further research is done to identify, possibly typify and evaluate the effect of different membership functions on the performance of sequencing systems. 
We hope our development and results encourage researchers to further develop this exciting and promising application of fuzzy-logic.

\section{References}

Abumaizar, R.J. and Svestka, J.A. (1997) 'Rescheduling job shops under random disruptions', International Journal of Production Research, Vol. 35, No. 7, pp.2065-2082.

Bergmann, M. (2008) An Introduction to Many-Valued and Fuzzy Logic: Semantics, Algebras, and Derivation Systems, Cambridge University Press, Cambridge.

Bilkay, O., Anlagan, O. and Kilic, S.E. (2004) 'Job shop scheduling using fuzzy logic', International Journal of Advanced Manufacturing Technology, Vol. 23, Nos. 7-8, pp.606-619.

Conway, R.W., Maxwell, W.L. and Miller, L.W. (1967) Theory of Scheduling, Addison-Wesley, Publishing Company, Massachusetts.

Correa, H.L. and Correa, C.A. (2012) Administração de produção e operações: uma abordagem estratégica, 3rd. ed., Ed. Atlas, São Paulo.

Cowling, P.I. and Johansson, M. (2002) 'Using real-time information for effective dynamic scheduling', European Journal of Operational Research, Vol. 139, No. 2, pp.230-244.

Dubois, D. (2011) 'The role of fuzzy sets in decision sciences: old techniques and new directions', Fuzzy Sets and Systems, Vol. 184, No. 1, pp.3-28.

Dubois, D. and Prade, H. (1996) 'What are fuzzy rules and how to use them', Fuzzy Sets and Systems, Vol. 84, No. 2, pp.169-185.

Dubois, D., Fargier, H. and Fortemps, P. (2003) 'Fuzzy scheduling: modelling flexible constraints vs. coping with incomplete knowledge', European Journal of Operational Research, Vol. 147, No. 2, pp.231-252.

Hamundu, F.M., Baharudin, A.S. and Budiarto, R. (2012) 'Fuzzy Monte Carlo simulation for cost benefit analysis of knowledge management system investment', in Hou, H.T. (Ed.): New Research on Knowledge Management Technology, InTech., [S.I.], cap. 5, pp.71-86 [online] http://cdn.intechopen.com/pdfs-wm/29141.pdft (accessed 19 July 2014).

Karwowski, W. and Evans, G.W. (1986) 'Fuzzy concepts in production management research: a review', International Journal of Production Research, Vol. 24, No. 1, pp.129-147.

Kasabov, N.K. (1998) Foundations of Neural Networks, Fuzzy Systems, and Knowledge Engineering, The MIT Press, London.

Kathawala, Y. and Allen, W.R. (1993) 'Expert systems and job shop scheduling', International Journal of Operations \& Production Management, Vol. 13, No. 2, pp.23-35.

Klir, G.J. and Folger, T.A. (1988) Fuzzy Sets, Uncertainty, and Information, Prentice-Hall, New York.

Klir, G.J. and Yuan, B. (1995) Fuzzy Sets and Fuzzy Logic. Theory and Applications, Prentice-Hall, New York.

Knott, C., Hovell, L., Karimian, N. and Garibaldi, J. (2013) FuzzyToolkitUoN. Version 1.0, [online] Disponível em: http://CRAN.R-project.org/package=FuzzyToolkitUon (accessed 19 July 2014).

Kreipl, S. and Pinedo, M. (2004) 'Planning and scheduling in supply chains: an overview of issues in practice', Production and Operations Management, Vol. 13, No. 1, pp.77-92.

Lee, K.H. (2005) 'First course on fuzzy theory and applications', Advances in Soft Computing, Springer-Verlag, Berlin.

MacCarthy, B.L. and Liu, J. (1993) 'Addressing the gap in scheduling research: a review of optimization and heuristic methods in production scheduling', International Journal of Production Research, Vol. 31, No. 1, pp.59-79. 
Mamdani, E.H. and Assilian, S. (1975) 'An experiment in linguistic synthesis with a fuzzy logic controller', International Journal of Man-Machine Studies, Vol. 7, No. 1, pp.1-13.

McNeill, F.M. and Thro, E. (1994) Fuzzy Logic: A Practical Approach, Academic Press Limited, London.

Ouelhadj, D. and Petrovic, S. (2009) 'A survey of dynamic scheduling in manufacturing systems.', Journal of Scheduling, Vol. 12, No. 4, pp.417-431.

Pinedo, M. (2001) Scheduling: Theory, Algorithms and Systems, Prentice Hall, Englewood Cliffs.

R Core Team (2014) R: A Language And Environment For Statistical Computing, R Foundation for Statistical Computing [online] Disponível em: http://www.R-project.org/ (accessed 19 July 2014).

Rodger, J.A. (2014) 'Application of a fuzzy feasibility Bayesian probabilistic estimation of supply chain backorder aging, unfilled backorders, and customer wait time using stochastic simulation with Markov blankets', Expert Systems with Applications, Vol. 41, No. 16, pp.7005-7022.

Rodger, J.A., Pankaj, P. and Gonzalez, S.P. (2014) 'Decision making using a fuzzy induced linguistic ordered weighted averaging approach for evaluating risk in a supply chain', Journal Advances in Manufacturing Technology, Vol. 70, Nos. 1-4, pp.711-723.

Ross, T.J. (2004) Fuzzy Logic with Engineering Applications, 2nd ed., John Wiley \& Sons, New York.

Shukla, C.S. and Chen, F.F. (1996) 'The state of the art in intelligent real-time FMS control: a comprehensive survey', Journal of Intelligent Manufacturing, Vol. 7, No. 6, pp.441-455.

Slack, N., Chambers, S. and Johnston, R. (2007) Administração da Produção, Atlas, São Paulo.

Stoop, P.P.M. and Wiers, V.C.S. (1996) 'The complexity of scheduling in practice', International Journal of Operations \& Production Management, Vol. 16, No. 10, pp.37-53.

Verbruggen, H.B. and Bruijn, P.M. (1997) 'Fuzzy control and conventional control: what is (and can be) the real contribution of fuzzy systems?', Fuzzy Sets and Systems, Vol. 90, No. 2, pp.151-160.

Williamson, T. (1994) Vagueness, Routledge, London.

Zadeh, L.A. (1965) 'Fuzzy sets', Information and Control, Vol. 8, No. 3, pp.338-353. 


\section{Appendix 1 - One example}






\section{Appendix 1 - One example (continued)}

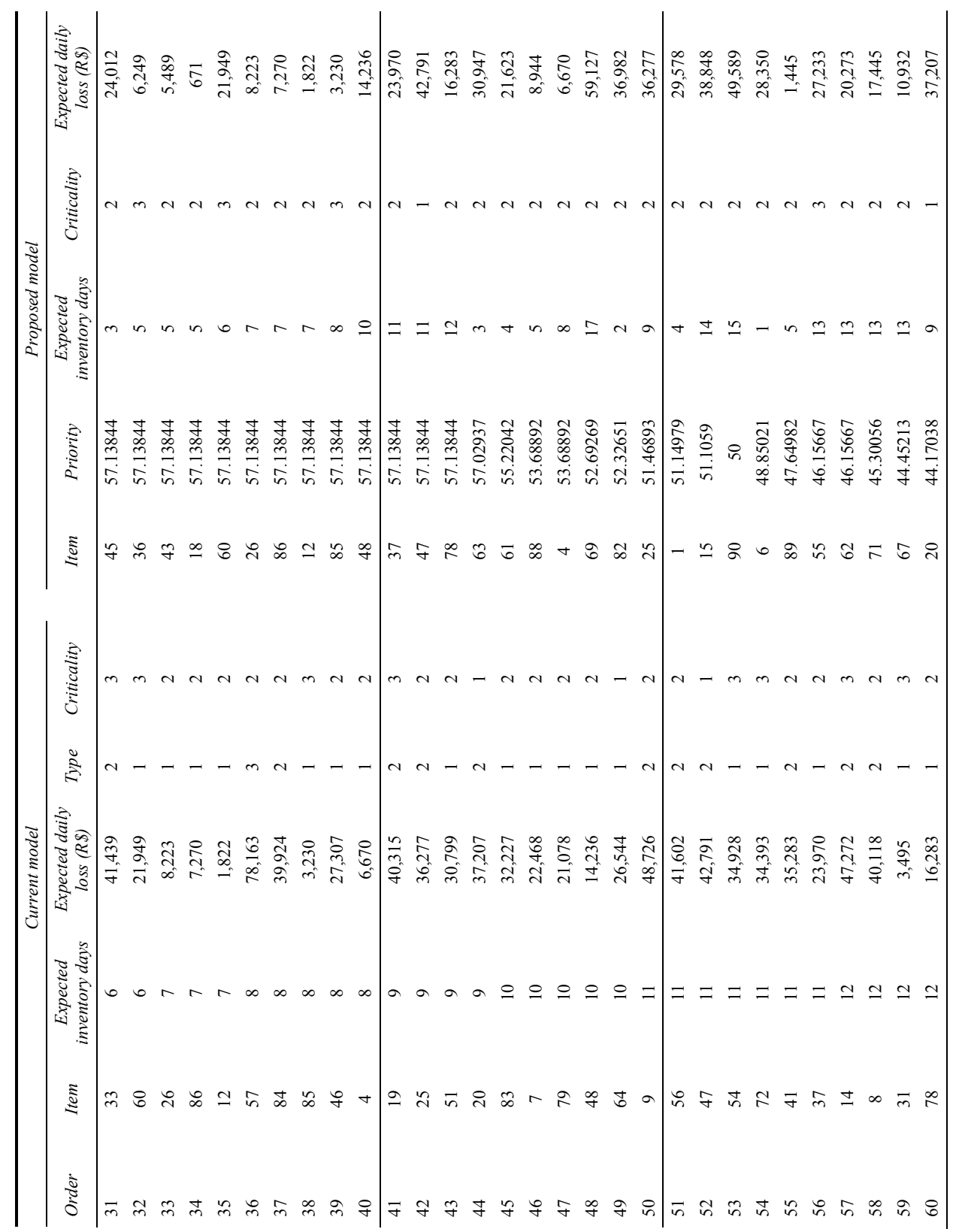




\section{Appendix 1 - One example (continued)}



